\title{
Testing of inhibition activity of essential oils against Paenibacillus larvae - the causative agent of American foulbrood
}

\author{
Katarína Kuzyšinová ${ }^{1}$, Dagmar Mudroňová ${ }^{2}$, Juraj Toporčák ${ }^{1}$, Radomíra Nemcová2, \\ Ladislav Molnár ${ }^{1}$, Aladár Mad'ari ${ }^{3}$, Slavomíra Vaníková ${ }^{4}$, Martin Kožár ${ }^{3}$ \\ ${ }^{1}$ University of Veterinary Medicine and Pharmacy, Clinic of Birds and Exotic Animals, ${ }^{2}$ Department of \\ Microbiology and Immunology, ${ }^{3}$ Clinic of Small Animals, Košice, Slovak Republic \\ ${ }^{4}$ Slovak Academy of Sciences, Institute of Animal Physiology, Košice, Slovak Republic
}

Received March 4, 2013

Accepted September 26, 2013

\begin{abstract}
American foulbrood is a dangerous world-wide spread disease of honey bees caused by the Paenibacillus larvae bacterium. Antibiotic treatments are less effective and leave residues in bee products. It is therefore necessary to find an alternative, especially using natural ingredients such as plant essential oils, probiotics, fatty or organic acids. Two strains of $P$. larvae were used for this study: CCM 4488, a strain from the Czech collection of micro-organisms and a Slovak field strain which was isolated from infected bee combs and characterized on the basis of biochemical properties. Plant essential oils of sage (Salvia officinalis), anise (Pimpinella anisum), oregano (Origanum vulgare), caraway (Carum carvi), thyme (Thymus vulgaris), rosemary (Rosmarinum officinalis), clove (Syzygium aromaticum), camomile (Chamomilla recutita) and fennel (Foeniculum vulgare) were used for the testing of the inhibitory activity against $P$. larvae. Essential oils at amounts of $5 \mu 1$ and $10 \mu 1$ were applied to sterile discs on MYPGP agar; inhibition zone diameters were measured after $24-\mathrm{h}$ incubation at $37{ }^{\circ} \mathrm{C}$. The strongest inhibitory activity against both $P$. larvae strains was noted in case of the essential oils from oregano, thyme and clove; essential oils from camomile, rosemary and fennel showed no or weak antibacterial activity. Medium strong inhibition activity was recorded in case of previously untested essential oil from Carum carvi. There was a difference in sensitivity of both tested strains to essential oils. Our study confirmed that some essential oils can be used in the prevention of American foulbrood but further experiments aimed at their influence on physiological intestinal microflora of honey bees must be performed.
\end{abstract}

Honey bees, Paenibacillus larvae, plant extracts, suppression, growth

American foulbrood is one of the most serious diseases of honey bees, resulting in high mortality rates; it is spread worldwide and causes major economic losses. It has been classified as a disease subject to the reporting obligation in terms of the OIE (World Organisation for Animal Health) list of transmissible diseases. The disease is caused by the Gram-positive rod-shaped bacterium, Paenibacillus larvae (Alippi and Aguilar 1998), surviving for long periods of time in the form of spores (Veselý et al. 2009). Application of antibiotics is of minor effect as the antibiotics affect only vegetative forms of $P$. larvae, while the spores continue to spread. Moreover, residues of antibiotics remain in bee products, primarily in honey, contributing to the increasing antibiotic resistance of pathogens. These are the reasons why the application of antibiotics against American foulbrood has been prohibited under the European Union legislation. Infection by $P$. larvae is handled in a radical way by eradicating the hives and all the combustible material by burning. Various teams of scientists are therefore trying to find some alternative to the use of antibiotics, and plant essential oils represent one of the promising possibilities. Many of the essential oils have antimicrobial properties and minimal or no side effects on the host organism (Rada et al. 2009). 
This study deals with the testing of the ability of selected plant essential oils to inhibit the growth of $P$. larvae.

\section{Materials and Methods}

Two strains of Paenibacillus larvae were used for the study: CCM 4488 (strain from the Czech collection of micro-organisms, isolated from dry scales and dead larvae from an apiary in Jarovnice, Slovakia), and Slovak field strain PL 02 which was isolated from infected bee combs (apiary in Kožany, Slovakia) at the Department of Microbiology and Immunology of the University of Veterinary Medicine and Pharmacy in Košice. This strain was identified on the basis of its biochemical properties and identification was confirmed by the MALDI-TOF MS (Matrix assisted laser desorption ionisation-time of flight mass spectrometry), where the raw spectra obtained for the isolate were imported into BioTyper software-version 2.0 and analysed without any user intervention (Bruker Daltonik GmbH, Leipzig, Germany).

For the testing of the inhibitory activity against $P$. larvae, essential oils of the following plants were used: Salvia officinalis, Pimpinella anisum, Origanum vulgaris, Carum carvi, Thymus vulgaris, Rosmarinum officinalis, Syzygium aromaticum, Chamomilla recutita and Foeniculum vulgare (Calendula, Slovakia).

The ability of the plant essential oils to inhibit the growth of $P$. larvae was examined using the in vitro disc method. Concentrated essential oils at amounts of $5 \mu \mathrm{l}$ and $10 \mu \mathrm{l}$ were applied to sterile discs with the diameter of $6 \mathrm{~mm}$ (BBL, Becton Dickinson, USA). Inhibition zone diameters were measured after a 24-h incubation at $37^{\circ} \mathrm{C}$ on MYPGP agar consisting of $10 \mathrm{~g}$ Müller-Hinton agar, $15 \mathrm{~g}$ yeast extract, $3 \mathrm{~g} \mathrm{~K}_{2} \mathrm{HPO}_{4}, 2 \mathrm{~g}$ glucose, $1 \mathrm{~g}$ sodium pyruvate and $20 \mathrm{~g}$ agar with $\mathrm{pH} 7.4$.

\section{Results}

Inhibitory activity of plant essential oils (applied at the amount of $5 \mu$ to the disc) against both $P$. larvae strains is presented in Table 1 . The strongest inhibitory activity against the Slovak field strain of

Table 1. Inhibitory activity of plant essential oils against Paenibacillus larvae of two strains (Slovak field strain and CCM 4488) expressed in terms of the diameter of the inhibition zone $(n=3)$.

\begin{tabular}{lcc}
\hline Essential oil $(5 \mu \mathrm{l})$ & Slovak field strain & CCM 4488 \\
\hline Salvia officinalis & $0.33 \pm 0.47$ & $0.93 \pm 0.09$ \\
Foeniculum vulgare & 0 & $0.77 \pm 0.05$ \\
Pimpinella anisum & 0 & $0.73 \pm 0.05$ \\
Origanum vulgaris & $2.63 \pm 0.29$ & $2.17 \pm 0.12$ \\
Carum carvi & $1.40 \pm 0.49$ & $1.00 \pm 0.08$ \\
Thymus vulgaris & $2.63 \pm 0.26$ & $2.13 \pm 0.26$ \\
Rosmarinum officinalis & 0 & 0 \\
Chamomilla recutita & 0 & 0 \\
Syzygium aromaticum & $1.77 \pm 0.34$ & $1.40 \pm 0.08$ \\
\hline
\end{tabular}

Data are expressed as average of the diameters of the inhibition zones in $\mathrm{cm} \pm \mathrm{SD}$. $P$. larvae was recorded in case of the essential oils from Thymus vulgaris (Plate I, Fig. 1) and Origanum vulgaris. In contrast, essential oils from Foeniculum vulgare, Pimpinella anisum, Rosmarinum officinalis (Plate I, Fig. 2) and Chamomilla recutita showed no inhibitory activity against the Slovak field strain of $P$. larvae. Results obtained for CCM 4488 strain were similar to those obtained for the Slovak field strain, however, the CCM 4488 strain was more susceptible to the essential oils from Foeniculum vulgare and Pimpinella anisum.

Inhibitory activity of plant essential oils (applied at the amount of $10 \mu$ l to the disc) against both $P$. larvae strains is presented in Table 2 . The strongest inhibition of growth of the Slovak field strain of $P$. larvae was recorded in essential oils from Thymus vulgaris, followed by Origanum vulgaris (Plate I Fig. 3), and Syzygium aromaticum. Growth of the Slovak field strain of $P$. larvae was not inhibited by the essential oils from Foeniculum vulgare and Chamomilla recutita. The growth of CCM 4488 strain of P. larvae was inhibited especially by application of essential oils from Origanum vulgaris and Thymus vulgaris and with lower effect in case of the essential oils from Syzygium aromaticum. In contrast, essential oils from Chamomilla recutita (Plate I, Fig. 4) showed no inhibitory activity. 
Table 2. Inhibitory activity of plant essential oils against Paenibacillus larvae of two strains (Slovak field strain and CCM 4488) expressed in terms of the diameter of the inhibition zone $(n=3)$.

\begin{tabular}{lcc}
\hline Essential oil $(10 \mu \mathrm{l})$ & Slovak field strain & CCM 4488 \\
\hline Salvia officinalis & $0.73 \pm 0.05$ & $1.13 \pm 0.12$ \\
Foeniculum vulgare & 0 & $0.87 \pm 0.05$ \\
Pimpinella anisum & $0.93 \pm 0.09$ & $0.87 \pm 0.05$ \\
Origanum vulgaris & $2.73 \pm 0.17$ & $2.63 \pm 0.24$ \\
Carum carvi & $1.40 \pm 0.14$ & $1.30 \pm 0.08$ \\
Thymus vulgaris & $3.13 \pm 0.12$ & $2.47 \pm 0.05$ \\
Rosmarinum officinalis & $0.77 \pm 0.05$ & $0.77 \pm 0.05$ \\
Chamomilla recutita & 0 & 0 \\
Syzygium aromaticum & $2.07 \pm 0.54$ & $1.40 \pm 0.08$
\end{tabular}

Data are expressed as average of the diameters of the inhibition zones in $\mathrm{cm} \pm \mathrm{SD}$. and others (Alippi et al. 1996; Floris et al. 1996; Albo et al. 2001, 2003). Based on the determination of minimal inhibitory concentrations, Alippi et al. (1996) found the highest activity against $P$. larvae in essential oils from Cymbopogon Citratus (MIC $=50$ $100 \mu \mathrm{l} / \mathrm{l})$, Thymus vulgaris $(\mathrm{MIC}=100-150 \mu \mathrm{l} / 1)$ and Origanum vulgaris $(\mathrm{MIC}=250$ $350 \mu \mathrm{l} / \mathrm{l}$ ). In our study, we also noted the strongest antimicrobial activity in the essential oils from Thymus vulgaris and Origanum vulgaris. Fuselli et al. (2006) recorded high antimicrobial activity of the essential oils from Thymus vulgaris against $P$. larvae with MIC ranging from 150 to $250 \mu \mathrm{l} / 1$. Moreover, they used the essential oils from Mentha piperita and Acantholippia seriphioides, which showed the strongest inhibitory activity against the causal agent of the American foulbrood. Özkirim et al. (2012) found the strongest antibacterial activity against $P$. larvae possessed by essential oil from Origanum onites, however, Rosmarinum officinalis, Seseli andronakii, Pimpinella anisum, Heracleum platytaenium, Anethum graveolens, Bifora radians and Seseli tortuosum also showed significant inhibition of the growth of P. larvae. In contrast to this study, we found no or weak antibacterial activity of Rosmarinum officinalis and Pimpinella anisum against $P$. larvae. Medium strong inhibition activity was recorded in case of the previously untested essential oil from Carum carvi. Rada et al. (2009) tested different plants for inhibitory activity against $P$. larvae and found extracts from Melia azadirachta, Cinnamomum verum and Cymbopogon Citratus as the most effective. Klouček et al. (2008) determined the activity of essential oils in the gaseous phase in vitro. The strongest effect was recorded in the essential oils from Armoracia rusticana, followed by Thymus vulgaris, Mentha piperita and Satureja hortensis.

In both strains tested, the strongest inhibitory activity was recorded in the essential oils from Origanum vulgaris, Thymus vulgaris and Syzygium aromaticum, which seem to be promising as to their use in prevention of the American foulbrood. Resistance to essential oils is strain dependent, since only the Slovak field strain was resistant to the essential oils from Pimpinella anisum and Foeniculum vulgare. Alippi et al. (1996) tested the antibacterial activity of 8 essential oils against 8 strains of Paenibacillus larvae isolated from honeycombs of hives exhibiting clinical symptoms of American foulbrood, noting only slight differences among the strains tested.

In terms of practise, the use of essential oils in hives can present certain problems, as application of the same essential oil to more hives in one apiary could cause misorientation of bees due to their intensive aroma. 
Our study confirmed that some essential oils can be used in the prevention of American foulbrood, but further experiments aimed at their influence on the physiological intestinal microflora of honey bees and application to the hives must be performed.

\section{Acknowledgements}

The study was financially supported by the Slovak Scientific Agency VEGA, project no. 2/0016/12.

\section{References}

Albo GN, Cerimele E, Re MS, De Giusti M, Alippi A 2001: Fouldbrood: field trials for evaluating the effectiveness of some essential oils (In Spain). Vida Apícola 108: 41-46

Albo GN, Henning C, Ringuelet J, Reynaldi FJ, De Giusti MR, Alippi A 2003: Evaluation of some essential oils for the control and prevention of American Foulbrood disease in honey bees. Apidologie 34: 417-437

Alippi AM, Aguilar OM 1998: Unique DNA fingerprint patterns of Paenibacillus larvae subsp. larvae strains. J Apicult Res 37: 273-280

Alippi AM, Ringuelet JA, Cerimele EL, Re MS, Henning CP 1996: Antimicrobial activity of some essential oils against Paenibacillus larvae, the causal agent of American Foulbrood disease. J Herbs Spices Med Plants 4: 9-16

Floris I, Carta C, Moretti M 1996: Activity of various essential oils against Bacillus larvae White in vitro and in apiary trials (In Spain). Apidologie 27: 111-119

Fuselli SR, Garcia De La Rosa SB, Gend LB, Eguaras MJ, Fritz R 2006: Antimicrobial activity of some Argentinean wild plant essential oils against Paenibacillus larvae, casual agent of American Foulbrood (AFB). J Apicult Res 45: 2-7

Klouček P, Flesar J, Kokoska L, Nedorostová L, Titera D 2008: Activity of essentials oils vapoure phase against Paenibacillus larvae. Planta Medica 74: 1038

Özkirim A, Keskin N, Kürkçüoğlu M, Hüsnü Can Başer K 2012: Evaluation of some essential oils as alternative antibiotics against American foulbrood agent Paenibacillus larvae on honey bees Apis mellifera L. J Essent Oil Res 24: 465-470

Rada V, Havlík J, Flesar J 2009: Biologically active substances in the nutrition of bees (In Czech). Výzkumný ústav živočišné výroby (Research Institute of Animal Production). Praha, Uhříněves, pp. 27-50

Szabóová R, Lauková A, Chrastinová L', Strompfová V, Pogány Simonová M, Plachá I, Vasilková Z, Chrenková M, Faix S 2012: Benefficial effect of plant extracts in rabbit husbandry. Acta Vet Brno 81: 245-250

Veselý V, Bacílek J, Čermák K, Drobníková V, Haragsim O, Kamler F, Krieg P, Kubišová S, Peroutka M, Ptáček V, Skkrobal D, Titěra D 2009: Beekeeping (In Czech). Praha, Nakladatelství Brázda, pp. 209-211 